\title{
Erratum to: Perineural tumor spread of bladder cancer causing lumbosacral plexopathy: an anatomic explanation
}

Daniel M. Aghion • Stepan Capek • Benjamin M. Howe • Jaroslaw T. Hepel • Sundaresan Sambandam •

Adetokunbo A. Oyelese • Robert J. Spinner

Published online: 21 November 2014

(C) Springer-Verlag Wien 2014

Erratum to: Acta Neurochir (2014) 156:2331-2336

DOI 10.1007/s00701-014-2257-8

The original version of this article contained a mistake. The name of Adetokunbo A. Oyelese was misspelled and is now corrected in the authorgroup of this article.

The online version of the original article can be found at http://dx.doi.org/ 10.1007/s00701-014-2257-8.

D. M. Aghion · A. A. Oyelese

Department of Neurosurgery, Warren Alpert Medical School of

Brown University, Providence, RI, USA

S. Capek $\cdot$ R. J. Spinner $(\bowtie)$

Department of Neurosurgery, Mayo Clinic, Rochester, MN, USA

e-mail: spinner.robert@mayo.edu

S. Capek

International Clinical Research Center, St. Anne's University

Hospital Brno, Brno, Czech Republic

B. M. Howe

Department of Radiology, Mayo Clinic, Rochester, MN, USA

J. T. Hepel

Department of Radiation Oncology, Warren Alpert Medical School

of Brown University, Providence, RI, USA

S. Sambandam

Department of Oncology, Rhode Island Hospital, Providence, RI,

USA 